BERKALA FISIKA INDONESIA

\title{
Penentuan temperatur curie pada kawat nikel berarus listrik dengan metode pendulum
}

\author{
Ramadanti Catur Khasanah ${ }^{1 *}$, Moh. Irma Sukarelawan ${ }^{2}$, Yudi Setyawati ${ }^{3}$ \\ 1 Pendidikan Fisika, Fakultas Keguruan dan Ilmu Pendidikan, Universitas Ahmad Dahlan, Indonesia \\ ${ }^{2}$ Magister Pendidikan Fisika, Fakultas Keguruan dan Ilmu Pendidikan, Universitas Ahmad Dahlan, Indonesia \\ ${ }^{3}$ SMP N 3 Selomerto, Wonosobo, Indonesia \\ Email: ramadanti1600007036@webmail.uad.ac.id* \\ * Penulis korespondensi
}

\begin{tabular}{l}
\hline Informasi artikel \\
\hline Sejarah artikel: \\
Dikirim \\
Revisi \\
Diterima \\
\hline Kata kunci: \\
Feromagnetik \\
Magnetisasi \\
Nikel \\
Paramagnetic \\
Temperatur curie \\
\hline
\end{tabular}

\section{Keywords:}

Ferromagnetic

Magnetization

Nickel

Paramagnetic

Curie temperature

\begin{abstract}
ABSTRAK
Telah dilakukan eksperimen tentang penentuan temperatur Curie pada kawat nikel (Ni) menggunakan metode pendulum. Eksperimen ini dilakukan dengan memvariasikan panjang kawat. Metode pendulum digunakan karena agar dapat memperjelas peristiwa lepasnya magnet pada kawat saat mencapai temperatur curie. Penentuan nilai teperatur curie menggunakan regresi linear antara Panjang kawat terhadap kuadrat tegangan. Data yang telah diperoleh dianalisis dengan pendekatan regresi linier menggunakan Microsoft Excel. Hasil penelitian menunjukkan nilai Temperatur curie kawat nikel sebesar $625 \mathrm{~K}$, tingkat kesesuaian terhadap teori sebesar $99 \%$.
\end{abstract}

This is an open access article under the CC-BY-SA license

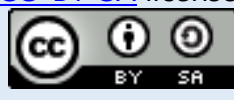

\begin{abstract}
Determination of curie temperature on electrically current nickel wire using the pendulum method. Experiments have been carried out on determining the Curie temperature on nickel (Ni) wire using the pendulum method. This experiment was carried out by varying the length of the wire. The pendulum method is used to clarify the event of the loss of the magnet on the wire when it reaches the curie temperature. Determination of the curie temperature using linear regression between the length of the wire to the square of the stress. The data that has been obtained were analyzed using a linear regression approach using Microsoft Excel. The results showed that the temperature value of the nickel wire curie was $625 \mathrm{~K}$, the level of conformity to theory was $99 \%$.
\end{abstract}

\section{How to Cite:}

Khasanah, R. C., Sukarelawan, M. I., \& Setyawati, Y. (2021). Penentuan temperatur curie pada kawat nikel berarus listrik dengan metode pendulum. Berkala Fisika Indonesia: Jurnal Ilmiah Fisika, Pembelajaran dan Aplikasinya, 12(1), 7-11 


\section{Pendahuluan}

Suhu atau temperatur Curie, disingkat $T_{C_{1}}$ merupakan karakteristik khusus dari bahan feromagnetik (Verma et al., 2010). Suhu curie adalah suhu di mana transisi fase feromagnetik material padat menjadi paramagnetik karena pemanasan, dan dapat diamati ketika terlepasnya suatu bahan feromagnetik, akibat dipanasi, dari magnet permanen (Fabian et al., 2013). Spin atom dalam bahan feromagnetik seperti besi $(\mathrm{Fe})$, nikel $(\mathrm{Ni})$, kobalt $(\mathrm{Co})$, dan paduannya secara spontan terpolarisasi, menjadikannya bersifat magnetis bahkan tanpa adanya medan magnet eksternal. Keadaan ini hanya terjadi pada saat suhunya lebih rendah dari suatu suhu karakteristik. Putarannya tampak acak di atas suhu karakteristik ini, memungkinkan keadaan berubah menjadi fase paramagnetik. Perubahan keadaan dari feromagnetik ke paramagnetik disebut fase transisi (Nursiyanto et al., 2017). Akibatnya, suhu transisi menjadi faktor kritis dalam fenomena ini (Rohman et al., 2020; Sudjatmoko, 2007).

Beberapa metode yang telah digunakan untuk menentukan temperatur curie di antaranya: metode keseimbangan torsi Chevallier (Ade-Hall et al., 1965), metode dua garis singgung (Grommé et al., 1969), metode ekstrapolasi dua garis singgung (Moskowitz, 1981), metode kawat berarus listrik (Kizowski et al., 2007; Okimustava \& Oktova, 2009), metode plot Arrott (Verma et al., 2010), metode kurva Ms(T) (Collinson, 2013), metode simulasi (Mardiansyah, 2013; Nursiyanto et al., 2017) dan berbasis Smartphone Magnetometer (Nuryadin \& Rusman, 2019), metode magnetocaloric (Moreno-Ramirez et al., 2016).

Metode lain yang dapat digunakan untuk menentukan temperatur Curie adalah metode pendulum. metode ini memanfaatkan pengamatan terhadap hilangnya sifat kemagnetan bahan. Penelitian ini difokuskan pada pengukuran temperatur curie pada kawat nikel. Kelebihan dari eksperimen ini yaitu mudah dalam mengamati saat terjadinya temperatur curie pada kawat, dikarenakan saat kawat nikel sudah mencapai temperatur curie maka bandul magnet akan terlepas dari kumparan. Hal tersebut dapat dijadikan sebagai indikator bahwa kawat nikel telah sampai pada fase transisi (curie). Oleh karena itu, penelitian ini bertujuan untuk menggunakan metode pendulum dalam menentukan temperatur curie kawat nikel.

\section{Metode}

Penelitian ini merupakan jenis penelitian eksperimen. Bahan yang akan ditentukan temperatur Curie adalah kawat nikel yang divariasi panjangnya. Penentuan temperatur Curie menggunakan metode pendulum. Pengambilan dilakukan di Lab Fisika kampus 2, Universitas Ahmad Dahlan. Pertama, merangkai alat berupa satu set statif dengan siku di bagian atas untuk meletakkan bandul dari magnet permanen type ferit berbentuk ring dengan diameter luar sebesar $6 \mathrm{~cm}$, diameter lubang sebesar 2,5 $\mathrm{cm}$, dan tebal magnet sebesar $1 \mathrm{~cm}$. Kemudian di bagian tengah statif terpasang pula besi yang sudah di beri penjepit kertas dan kabel penghubung untuk meletakkan kawat kumparan sepanjang $3 \mathrm{~m}, 5 \mathrm{~m}$ dan $7 \mathrm{~m}$, dengan diameter (d) $2 \mathrm{~mm}$. Sumber tegangan terus dinaikkan hingga magnet terlepas dari 
kawat. Aliran listrik pada kumparan menggunakan Slide Regulator. Multimeter digunakan untuk mengetahui besar tegangan dan hambatan saat terjadinya transisi (curie) pada kumparan. Prosedur ini dilakukan berulang sebanyak 5 kali setiap kawat dengan panjang berbeda. Gambar 1 menunjukkan rangkaian bandul penentuan temperatur curie.

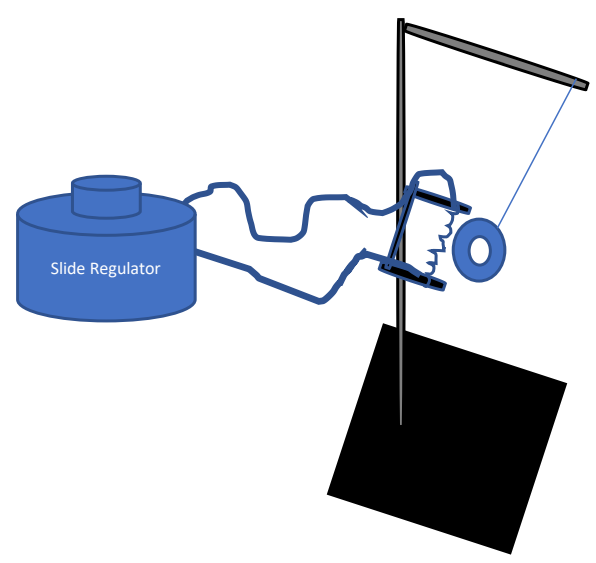

Gambar 1. Rangkaian Alat Percobaan

Penentuan nilai Temperatur curie $\left(T_{c}\right)$ dapat menggunakan persamaan (1). Persamaan (1) dapat diselesaikan dengan menggunakan pendekatan regresi linear yang memiliki slope sebagaimana persamaan (2). Persamaan (2) dapat dimodifikasi untuk mendapatkan nilai $T_{\mathrm{c}}$ dan mengikuti persamaan (3).

$$
\begin{aligned}
V^{2} & =e \sigma \pi d R\left(T_{c}^{4}-T_{0}^{4}\right) L \\
a_{1} & =e \sigma \pi d R\left(T_{c}^{4}-T_{0}^{4}\right) \\
T_{c} & =\sqrt[4]{\frac{a_{1}}{e \sigma \pi d R}+T_{0}^{4}}
\end{aligned}
$$

Dimana $T_{\mathrm{c}}=$ Temperatur curie, $a_{1}=$ kemiringan garis, $e=$ emisivitas nikel $\left(0.045\right.$ pada suhu $\left.25^{\circ} \mathrm{C}\right)$, $\sigma=$ konstanta Stefan-Boltzmann, $d=$ diameter kawat $(0.002 \mathrm{~m}), R=$ hambatan kawat, dan $T_{\mathrm{o}}=$ temperatur mula-mula. Nilai diskripansi pengukuran ditentukan menggunakan persamaan (4).

$$
\mathrm{Z}=\left|\frac{T_{c-\text { pengukuran }}-T_{c-\text { literatur }}}{T_{c-\text { literatur }}}\right| \times 100 \%
$$

\section{Hasil dan Pembahasan}

Dari eksperimen yang telah dilakukan diperoleh nilai tegangan, dan hambatan sebagaimana ditampilkan dalam Tabel 1.

Tabel 1. Data eksperimen

\begin{tabular}{cccc}
\hline $\boldsymbol{L}(\mathbf{m})$ & $\boldsymbol{V} \mathbf{c}(\mathbf{v o l t})$ & $\boldsymbol{R}(\boldsymbol{\Omega})$ & $\boldsymbol{T}_{\boldsymbol{o}}(\mathbf{K})$ \\
\hline 3,00 & 24,50 & 47,08 & 298,60 \\
5,00 & 27,06 & 55,88 & 299,40 \\
7,00 & 32,18 & 118,90 & 300,00 \\
\hline
\end{tabular}


Setelah pengambilan data pada eksperimen, data diolah menggunakan Microsoft Excel. Berdasarkan data yang diperoleh diketahui bahwa semakin panjang kawat yang digunakan, tegangan yang dibutuhkan untuk melepaskan kawat dari magnet permanen semakin besar. Hal ini karena untuk dapat membuat arus mengalir ke semua permukaan kawat membutuhkan tegangan yang besar agar arus yang dihasilkan juga besar. Dari data-data yang diperoleh kemudian dilakukan analisis regresi linier $v^{2}$ terhadap $L$ menggunakan Microsoft Excel. Grafik hasil analisis regresi linier dengan menggunakan Ms Excel dapat dilihat pada Gambar 1.

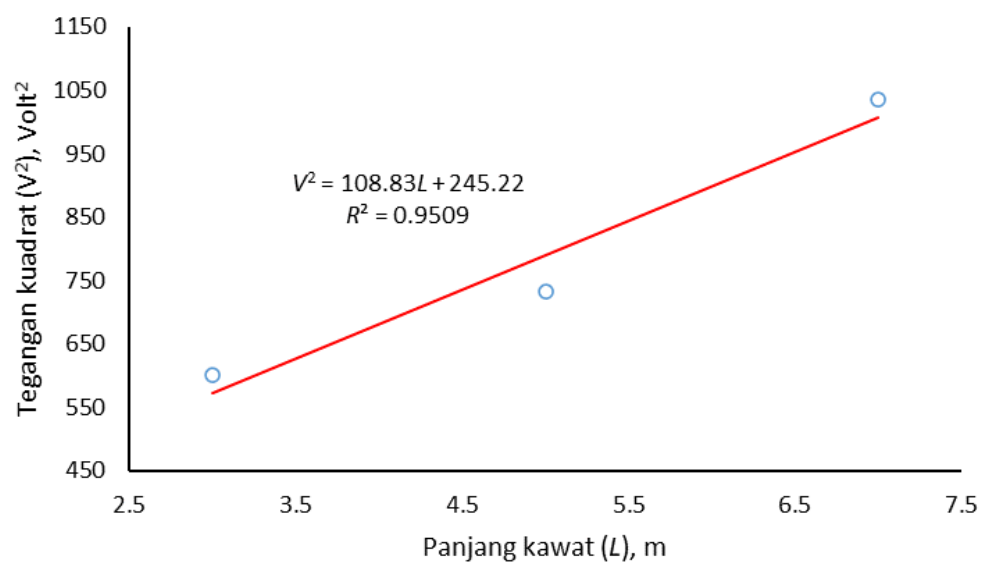

Gambar 1. Grafik hubungan antara $V^{2}$ dengan panjang kawat $(L)$

Gambar 1 menunjukkan hasil regresi linier antara tegangan kuadrat terhadap panjang kawat. Berdasarkan Gambar 1 diperoleh nilai kemiringan garis (slope). Menggunakan persamaan (3), nilai temperatur curie masing-masing panjang kawat sebesar 625K. Nilai yang diperoleh ini mendekati nilai dalam literatur, sebesar 631K (Evans et al., 2014). Besar diskripansi antara hasil pengukuran dan literatur sebesar $0,96 \%$. Nilai ini menunjukkan adanya kesesuaian yang baik antara hasil pengukuran dan nilai teori.

\section{Simpulan}

Suhu curie adalah suhu yang dicapai ketika terjadinya perpindahan fase sifat kemagnetan material padat dari feromagnetik menjadi paramagnetik. Perpindahan fase ini dapat terjadi akibat adanya pemanasan. Suhu curie dapat diamati ketika terlepasnya bahan feromagnetik dari magnet permanen. Dari penelitian ini dapat disimpulkan bahwa besarnya temperatur curie kawat nikel sebesar 625K. Hasil temuan memiliki kesesuaian dengan literatur sebesar $99 \%$.

\section{References}

Ade-Hall, J. M., Wilson, R. L., \& Smith, P. J. (1965). The petrology, curie points and natural magnetizations of basic lavas. Geophysical Journal International, 9(4), 323-336.

Collinson, D. W. (2013). Methods in rock magnetism and palaeomagnetism: Techniques and instrumentation. Netherlands: Springer Science \& Business Media. 
Evans, R. F. L., Fan, W. J., Chureemart, P., Ostler, T. A., Ellis, M. O. A., \& Chantrell, R. W. (2014). Atomistic spin model simulations of magnetic nanomaterials. Journal of Physics: Condensed Matter, 26(10), 1-23.

Fabian, K., Shcherbakov, V. P., \& McEnroe, S. A. (2013). Measuring the curie temperatur. Geochemistry, Geophysics, Geosystems, 14(4), 947-961.

Grommé, C. S., Wright, T. L., \& Peck, D. L. (1969). Magnetic properties and oxidation of iron-titanium oxide minerals in Alae and Makaopuhi lava lakes, Hawaii. Journal of Geophysical Research, 74(22), 5277-5293.

Kizowski, C., Budzik, S., \& Cebulski, J. (2007). Finding the curie temperature for ferromagnetic materials. The Physics Teacher, 45(1), 31-33.

Mardiansyah, D. (2013). Analisa sifat ferromagnetik material menggunakan metode monte carlo. Jurnal Ilmiah Edu Research, 2(2), 65-74.

Moreno-Ramirez, L. M., Blazquez, J. S., Franco, V., Conde, A., Marsilius, M., Budinsky, V., \& Herzer, G. (2016). A New Method for Determining the Curie Temperature From Magnetocaloric Measurements. IEEE Magnetics Letters, 7, 1-4.

Moskowitz, B. M. (1981). Methods for estimating curie temperaturs of titanomaghemites from experimentalJs-T data. Earth and Planetary Science Letters, 53(1), 84-88.

Nursiyanto, W., Rohman, L., \& Eko M, A. (2017). Analisis diameter kritis dan suhu curie bahan parmalloy FeCoB berbentuk bola-nano serta pengaruh temperatur (heat assisted) dengan menggunakan program simulasi mikromagnetik NMAG dan Vampire. Spektra: Jurnal Fisika Dan Aplikasinya, 2(3), 187-194.

Nuryadin, B. W., \& Rusman, R. (2019). Simple determination of curie temperatur using a smartphone magnetometer. The Physics Teacher, 57(6), 422-423.

Okimustava, \& Oktova, R. (2009). Penentuan suhu curie besi dengan metode kawat berarus listrik. In Seminar Fisika dan Aplikasinya. Surabaya: Institut Teknologi Sepuluh November.

Rohman, L., Novitasari, S., \& Supriyadi. (2020). Temperatur curie dan medan koersivitas material $\mathrm{Co}_{0,8} \mathrm{Ni}_{0,2}$ dalam struktur random alloy dan double layers. Indonesian Journal of Applied Physics, 10(1), 1-7.

Sudjatmoko. (2007). Kajian transisi fase lapisan tipis ferromagnetik melalui pengamatan nilai resistivitas listrik sebagai fungsi suhu. In K. Abraha, Y. Arryanto, \& S. J. S (Eds.), PPI • PDIPTN 2007 (pp. 303-309). Yogyakarta: Pustek Akselerator dan Proses Bahan-BATAN.

Verma, A., Sundararaman, M., Singh, J. B., \& Nalawade, S. A. (2010). A new method for determining the curie temperature using a dilatometer. Measurement Science and Technology, 21(10), 105106. 